\title{
Molecular MRI of Atherosclerosis
}

\author{
B.C. Te Boekhorst and K. Nicolay \\ Department of Biomedical Engineering, Eindhoven University of Technology, \\ The Netherlands
}

\section{Introduction}

Atherosclerosis and its consequences contribute to more than $50 \%$ of mortality in Europe, the United States of America and many developed or developing countries (Schafers et al., 2010). The main pathologic substrate in atherosclerosis is the atherosclerotic lesion. The classical high-risk plaque is characterized by a large lipid core, a thin fibrous cap and many macrophages in the shoulder regions of the plaque (Falk et al., 1995; Stary et al., 1995). Rupture of the fibrous cap or, more subtle, erosion leads to exposure of the thrombogenic sub-endothelial matrix to blood leading to thrombus formation. Recurrent thrombosis or major atherothrombosis may lead to an acute cardiovascular event via sub(total) occlusion of the vessel of interest. Macrophages are the key mediators of plaque inflammation and progression (Lusis, 2000; Ross, 1999). Inflammatory activity can be evaluated at the cellular (macrophages and neutrophils) or sub-cellular (secreted enzymes, membrane-bound proteins) level. Sensitive and specific biomarkers of plaque inflammation and instability are highly desired for more accurate definition of high-risk plaques in high risk patient populations. At present, serologic markers do not accomplish this need sufficiently. Therefore, there is a need for noninvasive imaging techniques for identification and quantification of local plaque biomarkers, which can direct interventional cardiologists and vascular surgeons to diseased sites and can monitor therapeutic response.

\section{Atherosclerosis}

Atherosclerosis is characterized by various more or less orderly processes taking place during the development from a fatty streak to a rupture-prone or ruptured plaque (Ross, 1999). Several morphological stages of plaque development related to risk of rupture were described by the American Heart Association (Stary et al., 1995). However, recently other plaques than the classical vulnerable plaque with a large lipid core and thin fibrous cap were also recognized as high-risk plaque, like highly calcified and obstructive plaques (Naghavi et al., 2003a, 2003b). During the process of atherogenesis, inflammation aggravates endothelial dysfunction and vice versa. First, low density lipoproteins are deposited in the subintima, where rare neutrophils and macrophages produce myeloperoxidase. This leads to generation of tyrosyl radicals and aldehydes resulting in oxidation of LDL. Oxidized LDL (ox-LDL) irritates endothelial cells which become dysfunctional, leading to inflammatory cell migration and activation. Macrophage activation leads to release of 
matrix metalloproteinases, cathepsins and other matrix degrading enzymes. Activated macrophages also release factors that eventually cause apoptosis of smooth muscle cells, endothelial cells and macrophages themselves. Fibrous cap thinning, lipid core growth, formation of fragile intra-plaque neovasculature, intra-plaque hemorrhage and finally fibrous cap rupture may be the result of these processes. Fibrous cap rupture leads to exposure of the tissue under the broken endothelial barrier to the blood stream which activates coagulation. Subsequent formation of a thrombus may cause an acute thrombotic event (Libby, 2002; Lusis, 2000; Ross, 1999).

All these processes can serve as the target of molecular imaging techniques, at the cellular or subcellular/molecular level. The next section describes an overview of the available methods for in vivo molecular imaging of atherosclerosis.

\section{Molecular imaging techniques for atherosclerosis}

Various noninvasive imaging techniques are available for evaluation of the levels of the above inflammation-related cells, proteins or enzymes. Fluorescence imaging (FI), ultrasound (US), computed tomography (CT), positron emission tomography (PET), singlephoton-emission computed tomography (SPECT) and magnetic resonance imaging (MRI) are all imaging modalities with in vivo applicability that could play a role in molecular imaging of plaque inflammation (I.Y. Chen \& Wu, 2011).

Because light attenuation by tissue is wavelength dependent, fluorescent proteins with more red-shifted emission wavelength have been developed to maximize FI sensitivity and specificity. The advent of quantum dot technology alleviates the problems associated with protein-based optical reporters, e.g. photobleaching, low quantum yield, low absorbance and broad emission band. However, because of the limited imaging depth an intravascular catheter is needed for clinical application (Calfon et al., 2010). Further, cytotoxicity of quantum dots needs to be addressed and a second imaging modality (MRI or CT) is needed for anatomic colocalization before FI with quantum dots may be clinically implemented (Iga et al., 2007).

Ultrasound with targeted micro-bubbles is restricted to the endothelial molecular targets, because the size of the bubbles $(\sim 1-10 \mu \mathrm{m})$ precludes their extravasation (I.Y. Chen \& Wu, 2011). Other disadvantages of US include the high degree of operator dependency, low micro-bubble adhesion efficiency and poor ability to image past bony structures.

Recently, an iodinated CT contrast agent was used for imaging of macrophage activity in atherosclerotic plaques (Hyafil et al., 2007). The unknown toxicity of the high concentrations of organometallics needed for effective imaging, limited differentiation between diverse soft plaque constituents and the high radiation exposure limit clinical application of molecular CT.

After intravenous administration of the PET-tracer F-18-fluorodeoxyglucose, metabolically active cells may take up this tracer. This has been shown useful for PET/CT imaging of atherosclerotic plaque inflammation in carotid, iliac and femoral arteries of patients (Rudd et al., 2007). PET and SPECT are techniques allowing imaging of disease processes in vivo with nanomolar/picomolar sensitivity (Massoud \& Ghambir, 2003). SPECT was applied for imaging of plaque apoptosis in an atherosclerotic rabbit model (Kolodgie et al., 2003), and 
lipid-rich lesions of mice and rabbits via an epitope on ox-LDL (Tsimikas et al., 2000). PET and SPECT lack definition of anatomical structure and have limited spatial resolution, and therefore need to be combined with an imaging modality (CT or MRI), which can define anatomic structure.

In terms of broad clinical applicability and availability, MRI is the most versatile technique. MRI does not involve ionizing radiation, has a high penetration depth, is safe and noninvasive, suitable as a screening tool, which can be repeated at will and provides both anatomical and physiological information. Disadvantages of MRI are relatively long acquisition times and poor suitability for patients, who are claustrophobic. Molecular MRI of coronary artery plaque is difficult due to motion caused by respiration and cardiac contractions. These motions pose an upper limit to the time window of MRI signal acquisition during the cardiac cycle. However, development of more efficient pulse sequence protocols may reduce these problems in future.

Molecular MRI employs contrast agent carriers to which antibodies, peptides or receptor (ant)agonists with affinity for the target of interest are conjugated (Mulder et al., 2007a). Larger carriers can harbor a higher payload of MR contrast generating Gd or iron oxides and can therefore have higher relaxivity. However, carriers which are very large may not enter the plaque due to the limited size of endothelial cell fenestrations. In atherosclerosis these fenestrations may exceed the regular size of $5 \mathrm{~nm}$ by far. In the apoE-/- mouse model neo-intimal thickening of the carotid artery induced by a constrictive collar could be visualized with paramagnetic liposomes which could pass the endothelial barrier despite a mean diameter of $90 \mathrm{~nm}$ (Mulder et al., 2006). In another study the effect of size of the contrast agent on plaque permeation was investigated (Van Bochove et al., 2011). This effect was tested in apoE-/- mice in which a tapered cast around the right carotid artery generated thin cap fibroatheromas and non-thin cap fibroatheromas as published previously (Cheng et al. 2006). Low molecular weight Gd-chelates (Gd-HP-DO3A) and micelles led to plaque enhancement which was highest with the longest retention in the non-thin cap fibroatheromas, whereas liposomes did not accumulate in any of the plaques (Van Bochove et al., 2011). These results implicate that targeted liposomes are most suitable for the imaging of plaque-associated endothelial markers, whereas micelles, which accumulate extravascularly on a long timescale, are suited for imaging of less abundant markers inside plaques. Low molecular weight compounds may be employed for target-specific imaging of highly abundant extravascular plaque-associated targets.

\section{Molecular MRI of atherosclerosis}

\subsection{Extracellular matrix proteins}

The potential for in vivo molecular imaging of plaque collagen using a liposome functionalized with a collagen adhesion protein, CNA35, has been suggested after a series of in vitro tests (Sanders et al., 2009). Indirectly, quantification of collagen using this method could provide information about plaque phenotype, in particular plaque stability.

Another extracellular matrix protein of plaque, which has potential for noninvasive assessment of plaque burden by molecular MRI in vivo is elastin. Changes in elastin content and the high abundance of elastin during plaque development make it a good quantitative marker of plaque burden, which was recently confirmed in a mouse model of 
atherosclerosis with an elastin-specific MR contrast agent (Makowski et al., 2011). The strong MRI signal change provided by this agent allowed for imaging with high spatial resolution, not only resulting in accurate assessment of plaque burden, but also plaque characterization by quantification of intra-plaque elastin content using signal intensity measurements (Makowski et al., 2011).

Gadofluorine $\mathrm{M}$ is an amphiphile with perfluorinated side chains, which forms micelles with a diameter of 5 to $6 \mathrm{~nm}$ in aqueous solution. Accumulation of Gadofluorine M micelles in atherosclerotic plaque has been attributed to the enhanced vessel-wall permeability and also to its affinity for both extracellular matrix proteins (Meding et al. 2007) and plaque lipids (Barkhausen et al., 2003).

\subsection{Cholesterol deposition}

Antibody-conjugated paramagnetic micelles have been used for targeted MRI of specific epitopes of ox-LDL in atherosclerotic plaque. At 72 and 96 hours after intravenous injection of ox-LDL-targeted micelles in apoE-/- mice, specific MRI signal enhancement of aortic plaque was observed. MRI signal enhancement was significantly lower after injection of control non-conjugated micelles and nonspecific IgG-conjugated micelles (Briley-Saebo et al., 2008). Despite this success in the preclinical setting, clinical application of the ox-LDL targeted micelles may be hampered by the long blood circulation times (>14 hours) and high liver uptake (20\% of the injected dose). Cell apoptosis (Hak et al., 2009; Ide et al. 2005) and nephrogenic systemic fibrosis in patients with renal dysfunction (Pedersen, 2007) have been implied to be caused by gadolinium (Gd) released from paramagnetic MRI contrast agents. Therefore, excessive and prolonged retention of Gd-chelates in organs needs to be avoided.

Ox-LDL in the plaque of apoE-/- mice has also been targeted with functionalized lipidcoated ultra-small superparamagnetic iron particles (LUSPIOs) $(<20 \mathrm{~nm})$ (Briley-Saebo et al., 2011). The aortic wall was enhanced on gradient echo images after injection in apoE-/- mice using a positive contrast method (GRASP). In contrast, no enhancement was observed after injection of control non-targeted LUSPIOs and larger $(\sim 40 \mathrm{~nm})$ LSPIOs. In vivo specificity of the particles to ox-LDL increased after coating of the particles with lipids which prevented ingestion by macrophages.

Another targeted imaging approach which features interaction with plaque cholesterol is the use of HDL-like particles. These particles have the advantages of being endogenous and biodegradable, do not trigger immune reactions and are not recognized by the RES (Cormode et al., 2008, 2009; Frias et al., 2006; Skajaa et al., 2010). Other attractive biological properties of HDL-like particles are that HDL enables reverse cholesterol transport from the plaque, has anti-atherothrombotic properties, and reduces oxidation and plaque inflammation (Skajaa et al., 2010). Various versions of HDL-mimicking nanoparticles have been designed for plaque imaging: reconstituted HDL-like spherical or discoid particles, fully synthetic HDL-like particles and fully synthetic nanocrystal HDL (Cormode et al., 2009a; Skajaa et al., 2010). Spherical HDL-like particles were made up by apoA-I, extracted from human plasma, and reconstituted with commercially available phospholipids and Gdconjugated lipids (Frias et al., 2004). The signal intensity of the aortic wall of mice was highest at 24 hours after injection of the above particles and returned to baseline levels at 48 hours after injection (Frias et al., 2004). Cheaper and easier manufacturing procedures 
would facilitate the use of HDL-like particles. Two different methods of preparation of reconstituted HDL discs were compared for their in vivo efficacy of imaging aortic wall in apoE-/- mice (Frias et al., 2006). Both types of discs showed highest signal intensity of macrophage-rich plaques at 24 hours after injection, while advanced plaques containing more cholesterol crystals and less macrophages revealed most enhancement at 72 hours after injection (Frias et al., 2006). Two fully synthetic HDL-like disks based on two synthetic lipid-binding apo A-I mimicking peptides, 37pA and the cheaper and easier synthesized $18 \mathrm{~A}$, were compared for their potential for in vivo MR enhancement. At 24 hours after injection both HDL disks provided similar plaque enhancement in the aorta of atherosclerotic mice (Cormode et al., 2008). In nanocrystal HDL the natural HDL core is replaced by inorganic nanocrystals while retaining the phospholipid coating. Via modification of both their core and their corona, these particles can be made suitable for multimodality imaging. In one study Gd-chelates were incorporated in the corona while the nanocrystal core was chosen to be based on gold for CT detection, quantum dots for optical imaging or iron oxide (FeO) for MRI visualization (Cormode et al., 2008). In vivo MRI showed positive enhancement of plaque when the core consisted of gold or quantum dot, whereas a significant decrease in signal was observed when the core contained FeO. Histology revealed at least partial colocalization with plaque macrophages (Cormode et al., 2008). Additionally, all mentioned MRI-visible HDL-like nanoparticles might be useful to study the role of HDL in plaque progression (Skajaa et al., 2010).

As mentioned earlier, Gadofluorine $\mathrm{M}$ is supposed to have affinity for plaque lipids (Barkhausen et al., 2003) and extracellular matrix proteins. In a rabbit model of atherosclerosis injection of Gadofluorine $\mathrm{M}$ led to a high contrast-to-background ratio on $\mathrm{T}_{1^{-}}$ weighted MR images of aortic plaque (Barkhausen et al., 2003). The contrast-enhanced regions corresponded with Sudan-positive lipid-rich aortic wall segments on histological slices (Barkhausen et al., 2003).

\subsection{Endothelial cells}

Endothelial cells respond to several stimuli with increased expression of cell adhesion molecules. The inflammatory mediators, IL-1 and TNFa, are among these stimuli and lead to increased expression of ICAM-1, VCAM-1 and P-selectin by endothelial cells (Libby, 2002). Oxidized low-density lipoproteins, accumulating in plaque during atherogenesis, represent a stimulus for enhanced expression of VCAM-1 by endothelial cells (Libby, 2002; Lusis, 2000; Ross, 1999). Leukocytes extravasate after interaction of VCAM-1 with very late antigen-4 (VLA-4) on the leukocyte membrane surface (Libby, 2002).

The binding capacity of microparticles of iron oxide conjugated with antibodies directed against VCAM-1 (diameter $\sim 4.5 \mu \mathrm{m}$ ) to TNFa-stimulated mouse endothelial cells was demonstrated in vitro (McAteer et al., 2010). These VCAM-1-targeted microparticles were applied for in vivo imaging of inflammation in peritubular capillaries in murine kidneys after ischemia reperfusion injury (Akhtar, 2010). VCAM-1 expression on dysfunctional endothelial cells of cholesterol-fed apoE-/- mouse aorta was targeted with a cross-linked iron oxide (CLIO) fluorescent nanoparticle conjugated to a peptide sequence with homology to the a-chain of VLA-4 for both MRI and fluorescence imaging (Kelly et al., 2005). Higher signal amplification of atherosclerotic mouse aorta was anticipated and found by this group using newly developed second-generation VCAM-1-targeted magnetic nanoparticles that 
undergo internalization and trapping in endothelial cells and macrophages that express VCAM-1 (Nahrendorf et al., 2006).

P-selectin expression by endothelial cells has been imaged with a slow-clearing blood-pool MRI contrast agent functionalized with sulfate groups with homology to the P-selectin binding region of P-selectin glycoprotein ligand-1 (Alsaid et al., 2009). Application of this Pselectin-targeted paramagnetic agent led to specific plaque enhancement in apoE-/- mice between 10 and 30 minutes after intravenous injection. Ex vivo fluorescence microscopy confirmed specific binding of the agent to P-selectin (Alsaid et al., 2009).

\subsection{Neovascularization}

The reason for the development of neovasculature in atherosclerotic plaques is uncertain. One theory emphasizes the hypoxia in the thickened intimal layer $(>500 \mu \mathrm{m})$ as a stimulant for neoangiogenesis (Sluimer \& Daemen, 2009). Another theory however states that neovascularization may exist early on during atherogenesis and promotes plaque inflammation and progression by facilitating extravasation of inflammatory cells (Dunmore et al., 2007). Intraplaque hemorrhage of the fragile neovasculature has also been related to rapid carotid atherosclerotic plaque growth (Takaya et al., 2005).

Dynamic contrast enhanced (DCE) MRI was applied first for quantitative assessment of neovasculature in tumors, but has been exploited more recently for quantification of human carotid plaque neovasculature (Yuan et al., 2002). DCE-MRI uses serial MRI acquisitions with high temporal resolution enclosing a time window around the injection of a low molecular weight Gd-containing contrast agent. Differentiation between fibrous tissue (enhancement $\sim 80 \%$ ) and lipid core (enhancement $\sim 30 \%$ ) by virtue of the neovessel density in fibrous tissue has been demonstrated (Yuan et al., 2002). Quantitative information on plaque uptake kinetics of contrast agent, amount of neovascularization and vessel permeability may be provided by appropriate modeling of the signal intensity time course in the plaque (Calcagno et al., 2010).

Recently, Gadofluorine M uptake in the balloon-injured aorta of New Zealand White rabbits has been found to correlate with plaque neovessel and macrophage density (Sirol et al., 2009). Histological evaluation showed that plaque neovessels, lipid-rich regions and Gadofluorine M co-localized. However, non-specificity of Gadofluorine M, which also has affinity for other plaque constituents like extracellular matrix proteins and lipids, will complicate mathematical modeling of quantitative parameters.

Also targeted approaches have been used for the molecular MR imaging of plaque neovascularization. The $\alpha_{v} \beta_{3}$ integrin is expressed amongst others by endothelial cells on angiogenic vessels in plaque. A low molecular weight peptidomimetic of Arg-Gly-Asp conjugated to Gd-DTPA led to enhancement of aortic plaque in apoE-/- mice which was diminished after "presaturation" with the MRI-silent, Europium-chelated analogue of the Gd-conjugated compound (Burtea et al., 2008).

Targeting of proteins expressed on the outer endothelial cell membrane indicative for neovascularization has the distinct advantage that the contrast agent does not need to enter the plaque. This approach allows for the use of large, very potent, nanoparticulate MR contrast agents, like Gd-containing perfluorocarbon emulsion nanoparticles with a size of 
about $250 \mathrm{~nm}$ (Anderson et al., 2000). Transgenic rats with a mutation in the leptin receptor represent a model for metabolic syndrome, resulting in abdominal obesity, atherosclerosis and myocardial lesions. The Gd-containing perfluorocarbon emulsion targeted towards the $\alpha_{v} \beta_{3}$ integrin was used for imaging neovessels in aortic plaques of these rats (Cai et al., 2010). Additionally, the effect of treatment with the anorectic and hypolipidemic drug benfluorex on plaque neovascularization was studied. Treated animals displayed an overall lower and patchy plaque enhancement in comparison to non-treated ones, indicative for a decreased angiogenic vessel density in the plaque (Cai et al., 2010). So, modulation of neovascularization by therapeutics could be studied using this molecular MRI approach. The same $\alpha_{v} \beta_{3}$-targeted perfluorocarbon emulsion was used to monitor collateral formation after treatment with angiogenic L-arginine in a rabbit femoral artery ligation model (Winter et al., 2010). The results achieved in these diverse studies argue against a straightforward interpretation of MR imaging results in atherosclerosis using $\alpha_{v} \beta_{3}$-targeted nanoparticles. Molecular MRI of neovascularization with these nanoparticles may not discriminate between adverse plaque neovascularization and beneficial sprouting of collaterals. At the time, pharmacokinetic profiling information on $\mathrm{a}_{\mathrm{v}} \beta_{3}$-targeted and non-targeted perfluorocarbon nanoparticles has been obtained in rabbits with in vivo MRI and blood samples (Neubauer et al., 2008).

\subsection{Macrophages}

Macrophages play a key role in the inflammatory process of atherosclerosis. Therefore, they are most extensively studied using molecular MRI. Previously, superparamagnetic particles of iron oxide were used for lymph node imaging in the context of tumor staging and detection of focal liver lesions (Schmitz, 2003). During a phase III trial which investigated the use of the ultra-small dextran-coated counterparts of these particles (USPIOs, diameter 18-30 nm) for discrimination between healthy lymph nodes and lymph node metastases, these USPIOs were found by co-incidence to be ingested by aortic plaque macrophages (Schmitz et al., 2001). Since then these USPIOs have been extensively studied for their potential to monitor inflammation in atherosclerosis in patients and regression after treatment with aggressive lipid-lowering therapy (Tang et al., 2009).

The versatility of these USPIOs for imaging of both lymph nodes and atherosclerotic plaque constitutes an important drawback of these USPIOs. Lymph nodes often develop in close proximity to the inflamed plaque lesion. We have shown that differentiation between perivascular lymph nodes and aortic wall in atherosclerotic mouse models may be difficult using USPIOs (Te Boekhorst et al., 2010a). Successful visualization will depend on spatial resolution and the imaging sequence (Te Boekhorst et al., 2010a). Recently, a newly developed positive contrast technique for (U)SPIOs, "GRASP", has been shown capable to differentiate between peri-vascular lymph nodes and atherosclerotic vessel wall (BrileySaebo et al., 2011).

Apart from this cellular MRI approach, also specific macrophage membrane proteins have been targeted. Among others targeting of the macrophage scavenger receptor-A (MSR-A) has been achieved in a mouse model of atherosclerosis with paramagnetic Gd-containing micelles (Amirbekian et al., 2007). Plaques in the aortic wall of apoE-/- mice displayed a $79 \%$ increase in signal intensity upon injection of the MSR-A-targeted micelles, whereas control micelles resulted in 34\% signal increase (Amirbekian et al., 2007). MSR-A together 
with MSR-B is responsible for 75-90\% of ox-LDL uptake by macrophages. Ex vivo targeting of MSR-B in dissected human aortic atherosclerotic plaque has been achieved with 125-nmdiameter lipid-based nanoparticles (Lipinski et al., 2009). However, the potential of these MSR-B-targeted nanoparticles for in vivo targeting has still to be demonstrated. Bimodal micelles for MSR (A and B) containing both Gd and an optical label (rhodamine-conjugated lipid or a quantum dot) led to a signal increase of aortic wall in apoE-/- up to $200 \%$ (Mulder et al., 2007b). MSR-targeted rhodamine micelles could be detected with fluorescence microscopy and were found to be associated with macrophages. Quantum dots allowed ex vivo detection of aortic macrophage-rich regions with UV illumination (Mulder et al., 2007b).

Plaque macrophages express the ox-LDL receptor LOX-1 and binding of ox-LDL induces apoptosis, expression of adhesion molecules and release of MMPs (Ross, 1999; Li et al., 2010). Paramagnetic liposomes conjugated to anti-LOX-1 antibodies were injected in LDL-R-/- mice. Aortic plaques were specifically enhanced on T1 weighted MR images, while no enhancement was observed on MR images from double knockout LDL-R-/LOX-1-/- mice or from LDL-R-/- mice injected with nonspecific IgG-conjugated liposomes (Li et al., 2010). Histological analyses revealed that most LOX-1 co-localized with macrophages, apoptotic cells and MMP-9 and only a small proportion with proliferated smooth muscle cells.

The use of antibodies for making contrast agents target specific has important disadvantages: the high costs of antibodies, their immunogenicity and difficulty in handling and preparation. Application of other specific targeting moieties of non-antibody origin is therefore attractive. An example is the use of phosphatidylserine (PS) incorporated in selfassembled lipid-based contrast agents. PS is expressed on apoptotic cells and is specifically recognized by macrophages. PS-containing paramagnetic liposomes showed in vitro specificity for RAW cells (mouse macrophages) and significant MR enhancement of aortic plaques during the first 4 hours after injection in apoE-/- mice (Maiseyeu et al., 2009).

Another targeted approach avoiding the use of antibodies employs a potent synthetic agonist (HU-308) of the peripheral cannabinoid receptor (CB2-R) (Te Boekhorst et al., 2010b). T-lymphocytes and macrophages in advanced mouse and human atherosclerotic plaque CB2-R have been shown to express this CB2-R (Steffens et al., 2005). Activation of CB2-R by HU-308 results in amelioration of plaque phenotype in atherosclerotic mice (Steffens et al., 2005). The suggested mechanism is an immune system modulating effect through CB2-R, which involves a regulatory negative feedback effect dampening the inflammatory process in advanced plaques (Steffens et al., 2005). Self-assembly of polymeric micelles was easily achieved by mixing HU-308, which has a 7-carbon tail and a hydrophilic head group, with Gd-containing and PEG-ylated lipids (Te Boekhorst et al., 2010b). $\mathrm{T}_{1}$ weighted inversion recovery fast spin echo MR images revealed in vivo plaque enhancement in the aortas of double knockout apoE-/-, eNOS-/- mice between 36 and 48 hours after injection of CB2-R-targeted micelles (Te Boekhorst et al., 2010c).

The earlier mentioned flexible HDL platform could be easily functionalized for more specific retention into plaques. A third example of targeted approach avoiding the application of antibodies concerns incorporation of an apoE-derived lipopeptide into HDL particles enriched with Gd-based lipids (W. Chen et al., 2008). Application of this material led to both higher association with mouse macrophages in vitro and more pronounced in vivo 
enhancement of aortic plaque in mice relative to reconstituted HDL without incorporation of the apoE-derived lipopeptide (W. Chen et al., 2008).

Furthermore, hyaluronic acid, which targets the CD44 receptor on activated macrophages, has been conjugated to a lipid coating enclosing iron oxide nanoparticles (Kamat et al., 2010). In vitro experiments have revealed ingestion by activated THP-1 macrophages, suggesting potential for in vivo imaging of plaque inflammation (Kamat et al., 2010). Transient cellular location of the HDL particles was suggested by a series of Prussian blue stainings for iron. Despite these promising findings, the in vivo potential of these macrophage-targeted iron oxides for MRI of plaque inflammation has still to be confirmed.

Apart from direct targeting of macrophages, one can also address released macrophage products. An example of an extracellular released enzyme in atherosclerotic plaque is represented by the matrix metalloproteinases (MMPs). Increased activity of MMPs produced by smooth muscle cells and macrophages has been reported to be related to plaque rupture (Vink \& Pasterkamp, 2002; Schafers et al., 2010). A small peptide with affinity for MMPs was conjugated to Gd-DOTA and employed for in vivo MR imaging of plaque (Lancelot et al., 2008). The plasma half-life of this small peptide was only 30 minutes and the concentrations in artery specimens were 3 times as high as those after injection of Gd-DOTA, with prolonged retention at least until 22 hours after injection (Lancelot et al., 2008). The mentioned peptide has affinity for various MMPs. However, the MMP family is large and the role of each MMP member is not entirely known. It has been shown, that expression of MMP-2 and MMP-9 is upregulated in shoulder regions of human vulnerable plaques (Galis \& Khatri, 2002). The advent of specific inhibitors of MMP-9 and -2 and their application in small paramagnetic peptides may improve specificity for unstable plaque.

Another protein that has been linked to adverse cardiovascular events in patients after carotid endarterectomy surgery is neutrophil gelatinase-associated lipocalin-2 (NGAL) (Te Boekhorst et al., 2011). NGAL is produced and released particularly by macrophages, although first discovered in neutrophils (Hemdahl et al., 2006). MMP-9 activity is prolonged and degradation prevented after binding to NGAL. Apart from forming a stable and biologically active complex with MMP-9, NGAL mediates inflammatory activity through binding to formyl-methionyl-leucyl-phenylalanine (fMLP; a chemotactic peptide), leukotriene B4, and platelet-activating factor (Hemdahl et al., 2006). In vivo MRI of severely advanced atherosclerotic plaques of the double knockout apoE-/-, eNOS-/- mouse was performed at 24 and 72 hours after injection of 24p3(mouse homologue of NGAL)-targeted micelles and IgG isotype antibody-conjugated micelles (Te Boekhorst et al., 2011). Both 24p3-targeted and control micelles led to an increased average Normalized Enhancement Ratio (NER) at 24 hours after injection ( 1.45 versus $\sim 1.30$ respectively), while at 72 hours after injection of 24p3-targeted micelles average NER further increased and after injection of control micelles average NER had decreased ( 1.70 versus 1.20) (Te Boekhorst et al., 2011). Histology revealed that micelles co-localized with $24 \mathrm{p} 3$ and partially with macrophages. The results of this study are summarized in Figure 1A-H.

Targeting of extracellular located molecules such as MMPs and NGAL has the advantage over intracellular targets that the target is readily available. On the other hand, it may carry the drawback that the contrast agent is easily washed out from the plaque, together with the target, into the blood. Nevertheless, imaging of intact excreted proteins and particularly their activity could provide important insights in the inflammatory state of the plaque. For 

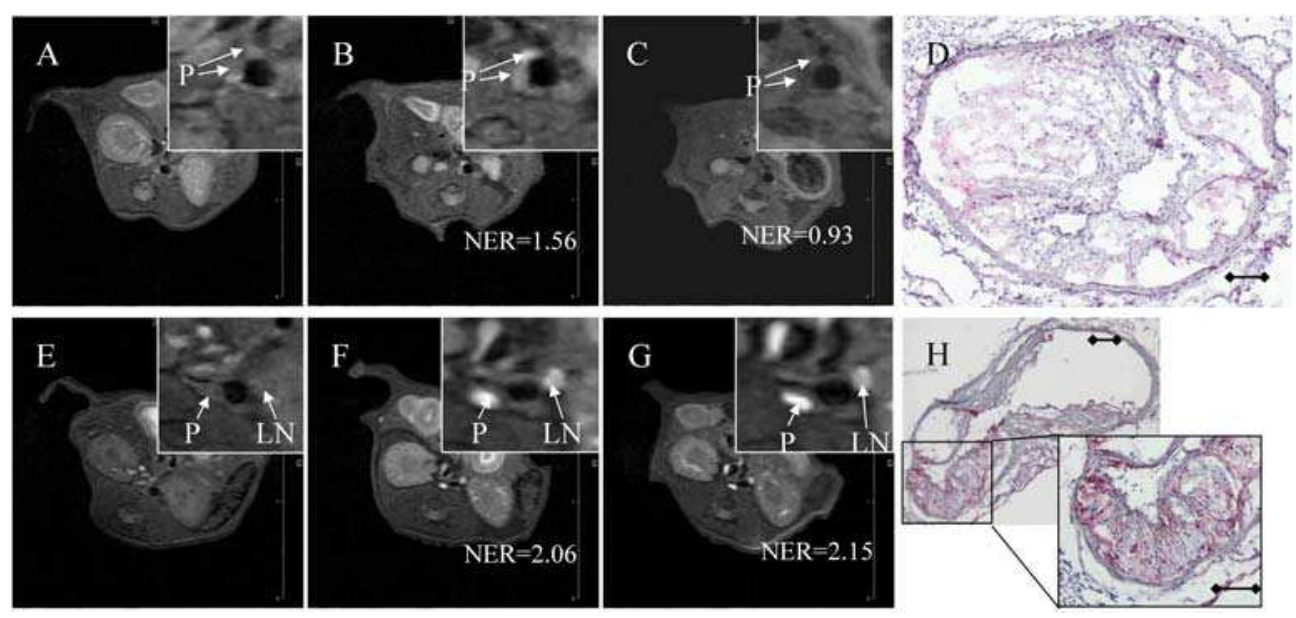

Fig. 1. MR images and histological stainings of atherosclerotic plaque after intravenous injection of NGAL/24p3-targeted micelles. Pre- and post-injection (0, 24 and $72 \mathrm{~h}) \mathrm{MR}$ images of aortic wall in apoE-/-/eNOS-/- mice injected with control (A-C) and NGAL/24p3targeted (E-G) micelles and immunohistochemistry at 72 hours for micelle-conjugated rat antibodies in control micelles (D) and NGAL/24p3-targeted micelles (H). P=plaque, LN=lymph node. NER= Normalized Enhancement Ratio. The post-injection MR images show increased signal intensity at 24 hours for both NGAL/24p3-targeted micelles and control micelles, while signal intensity at 72 hours stays at the higher level for NGAL/24p3targeted micelles but returned to baseline for control micelles. Note that the signal intensity of the peri-aortic lymph node, which was removed during harvesting of the aorta, is also increased after injection. Histology of the mouse aorta at 72 hours after injection revealed no staining of micelles for injections with control micelles and extensive red staining for injections with NGAL/24p3-targeted micelles.. H: scale bar $=100 \mu \mathrm{m}$ (original magnification: 100x) (Te Boekhorst et al., 2011).

example, peroxidase-based hematologic profiling has been shown to predict adverse cardiac events during a follow-up of 1 year (Brennan et al., 2010). In order to prevent washout of the agent, Bogdanov and coworkers have designed an activatable (smart) low-molecular weight Gd-containing probe for imaging of myeloperoxidase, an enzyme released by macrophages that is responsible for oxidation of LDL via the formation of reactive oxygen species (J.W. Chen et al., 2004). Activation of the probe by myeloperoxidase leads to polymerization, increasing its size and relaxivity, and prolonging its retention in the target region - hence providing an indirect readout of enzyme activity. This probe enabled MR imaging of increased myeloperoxidase activity in plaques in the aorta of rabbits, as is summarized in Figure 2A-G (Ronald et al., 2009). 

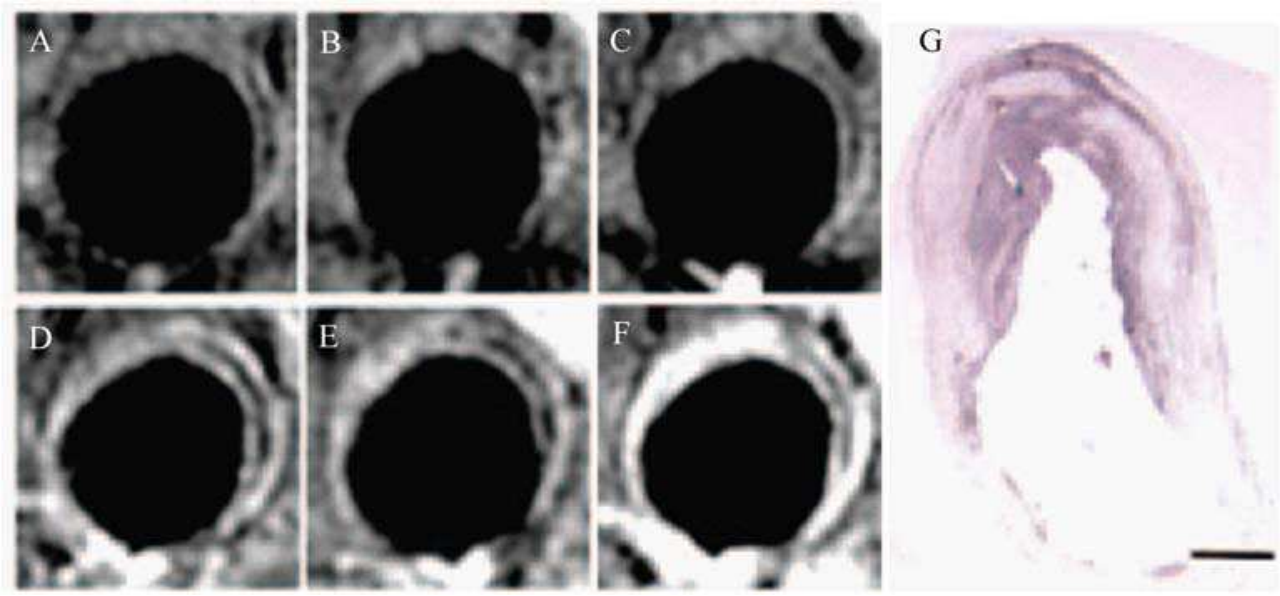

Fig. 2. Imaging of diseased aortas of cholesterol-fed rabbits before and after injection of an activatable MPO sensor.

Imaging before and 2 hours after injection of DTPA-Gd (A,D), before and 2 hours after injection of bis-tyr-DTPA-Gd (B,E) which is a nonactivatable analog of MPO-Gd, and before and 2 hours after injection of the functional agent MPO-Gd (C,F). Histology of the rabbit aorta after injection of MPO-Gd revealed focal MPO presence in the plaque and confirmed the MR findings (G). Printed with permission from (Ronald et al., 2009).

\subsection{Apoptotic cells}

When cells become apoptotic, phosphatidylserine (PS), initially mainly found in the inner leaflet of the viable cell membrane, is also expressed on the outer leaflet of the cell. The expression of PS can be detected with molecular MRI using the protein annexin A5 as a targeting ligand. Annexin A5 binds specifically to PS in the presence of calcium (Gerke et al., 2002). Apoptosis in atherosclerotic plaques in the aorta of apoE-/- mice was studied using Gd-containing micelles conjugated to annexin A5. $\mathrm{T}_{1}$-weighted MR images showed at 24 hours after injection a slight, but significant, increase of plaque intensity relative to control non-conjugated micelles (Van Tilborg et al., 2010).

Phage display may identify small peptides with specific affinity to selected targets. One study employed a PS-specific peptide, identified by phage display and conjugated to Gd-DTPA, for detection of apoptotic cells in aortic plaques of apoE-/- mice at 30 minutes after injection (Burtea et al., 2009). The use of such small peptides has certain advantages above proteins or antibodies in terms of reduced immunogenicity and a cheaper and easier production process.

However, studies with apoptosis-directed agents in a number of apoptosis-associated pathologies have also revealed the limitation of apoptosis-targeted contrast agents. The publication of a SPECT study reporting visualization of apoptosis of cardiomyocytes in patients with acute myocardial infarction (Hofstra et al., 2000) may serve as an example. Apoptosis may not be useful for targeted imaging of vulnerable plaque in the coronary 
arteries, due to the possibly overwhelming background signal of enhanced cardiac muscle in a compromised patient group.

\subsection{Activated platelets and thrombus}

Activated platelets play a crucial role in the formation of repetitive micro-thrombi, which suddenly may result in a major thrombus, followed by an acute cardiovascular event (Naghavi et al., 2003a, 2003b; Stary et al., 1995). Therefore, early recognition of a high incidence of micro-thrombi by molecular imaging of activated platelets has important prognostic value.

Activated platelets express aIIb $\beta 3$ integrin, which has been targeted with cyclic arginineglycine-aspartic acid (RGD) peptides, which are specific for the aII $\beta 3$ integrin among others, and are conjugated to ultra-small particles of iron oxide for T2* weighted MRI (Johansson et al., 2001). Unfortunately, the resolution, which was achieved with RGDUSPIO-enhanced MRI, was too low to detect thrombus in vivo (Johansson et al., 2001). Chemical conjugation to nanoparticles typically results in the loss of antibody functionality. A biochemically robust, highly reproducible and site-specific coupling method using the Staphylococcus aureus sortase A enzyme for the conjugation of single-chain antibodies $(\mathrm{scFv})$ to amine-coated superparamagnetic iron oxide nanoparticles was developed (Ta et al., 2011). Conjugation efficiency ranged between 50 and $70 \%$ and the bioactivity of the scFv with specific affinity to activated platelets was preserved after conjugation. In vivo MRI showed that these scFv-conjugated SPIOs effectively bound to activated platelets on $\mathrm{FeCl}_{3}$ induced thrombus in carotid arteries of mice (Ta et al., 2011).

Fibrin-targeted small peptides conjugated to Gd-DTPA have been employed successfully in pigs, showing the feasibility of MRI to differentiate between acute and subacute (1-3 days old) coronary thrombus (Botnar, 2004a, 2004b). More recently, MR enhancement of thrombus has been achieved in a phase II trial using these peptides in patients, with a diagnosed symptomatic thrombus in vessel territories potentially associated with stroke (Spuentrup et al., 2008).

Gd-perfluorocarbon nanoparticles functionalized with fibrin-targeted peptides were also applied for MR imaging of in vitro human thrombus (Winter et al., 2003). These perfluorocarbon nanoparticles can be used for $\mathrm{T}_{1}$-weighted proton MRI as well as for ${ }^{19} \mathrm{~F}$ hot-spot MR imaging. The advantage of the latter feature is the natural absence of background signal precluding the necessity of a baseline scan, which is attractive for clinical application from a logistical point of view.

Also contrast agents based on the paramagnetic chemical exchange saturation transfer (PARACEST) mechanism have been employed for MR imaging of fibrin. This technique has been pioneered by the group of Balaban et al. (Ward et al., 2000). PARACEST agents have exchangeable protons $(-\mathrm{NH},-\mathrm{OH}$, etc.) that resonate at a chemical shift position that is distinguishable from the bulk water signal. When an RF pulse is applied at the resonance frequency of the exchangeable protons, these protons will be saturated. Transfer into the bulk water pool will lead to reduced equilibrium magnetization. This so-called saturation transfer effect can be switched "on" and "off" by simply changing the pulse sequence. The PARACEST agents are potentially attractive for in vivo use, because contrast can be switched 
on and off by selective RF pulse saturation, avoiding the need for baseline imaging and spatial registration of images acquired hours or days apart. The main disadvantage of PARACEST agents, however, is low sensitivity, which hampers the ability to image molecular targets. One method of increasing the sensitivity of paraCEST agents is to incorporate multiple metal chelates into a macromolecular scaffold. Proof of concept CEST imaging of fibrin was provided in vitro for fibrin clots, using a fibrin-specific perfluorocarbon nanoparticle containing multiple PARACEST units (Winter et al., 2006). This first generation PARACEST nanoparticle agent, however, introduced a large cationic charge on the particle surface. Cationic particles can cause significant in vivo toxicity and are not suitable for biomedical applications. In a recent study, a neutral lipid conjugated PARACEST chelate was incorporated onto the surface of PFC nanoparticles leading to a negative surface charge. PARACEST and ${ }^{19} \mathrm{~F}$ MRI showed a linear increase in both PARACEST contrast to noise ratio and the 19F signal with increasing nanoparticle concentration. Artificial fibrin clots were efficiently targeted using these nanoparticles and imaged using PARACEST and ${ }^{19} \mathrm{~F}$ MRI (see Figure 3) with detection limits of $2.30 \mathrm{nM}$ and $4.60 \mathrm{nM}$ respectively (Cai et al., 2011).

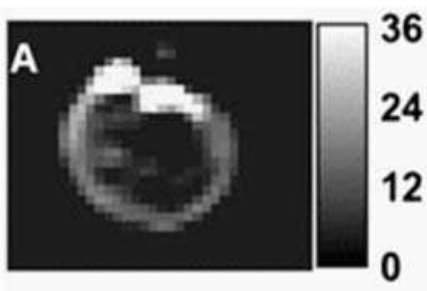

PARACEST

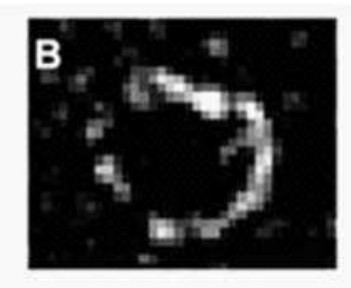

$19 \mathrm{~F}$
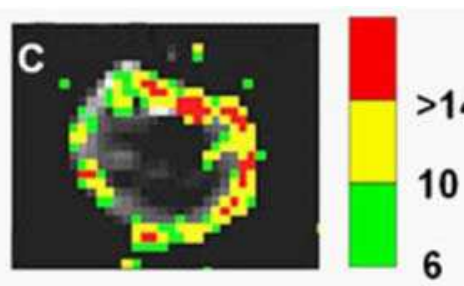

[NP] (nM)

Fig. 3. Dual PARACEST and ${ }^{19} \mathrm{~F}$ MR imaging of a clot treated with fibrin-targeted PARACEST nanoparticles.

PARACEST contrast to noise ratio map (A) and ${ }^{19} \mathrm{~F}$ image (B) collaboratively show nanoparticles bound to the surface of the clot. The grayscale color bar represents the PARACEST CNR depicted in (A). (C) The nanoparticle concentration (nM) is color-coded and overlaid onto the PARACEST subtraction image to demonstrate colocalization of these two definitive signals. Printed with permission from (Cai et al., 2011).

Various products of the coagulation cascade may serve as targets for molecular MRI as well. Very recently, a thrombin inhibitor was conjugated to perfluorocarbon nanoparticles for localized in vivo control of thrombus in the common carotid artery of a mouse after acute photochemical injury (Myerson et al., 2011). The modified nanoparticles outperformed heparin and the free thrombin inhibitor according to the activated partial thromboplastin time.

The earlier mentioned fibrin-targeted small-peptide MR contrast agents have low sensitivity for the estimation of thrombus age. Specific targeting of earlier phases of thrombus 
formation could help into this respect. Activated factor XIII cross-links fibrin chains and covalently cross-links a2-antiplasmin to fibrin, with a rapid decline in catalytic activity. Therefore, the potential of an a2-antiplasmin-based peptide labeled with rhodamine and Gd for specific detection of early thrombus was investigated both in vitro and in vivo (Miserus et al., 2009). Thrombus was induced via application of $\mathrm{FeCl}_{3}$ to the carotid artery of mice. In one group the contrast agent was injected seconds after thrombus formation, while in another group injection was postponed 24 to 48 hours after thrombus formation. Only early thrombus was enhanced using this contrast agent while thrombus with an age of $24-48$ hours was not enhanced (Miserus et al., 2009).

\section{View-to-future}

As described above, MRI is capable of providing detailed cellular and molecular imaging information, which combined with the wealth of anatomical and functional MRI readouts, makes MR imaging of atherosclerosis a very powerful asset to study plaque vulnerability, progression and to evaluate effects of treatment. A potential limitation of MRI, however, is the limited sensitivity of the technique in the detection of low concentrations of targeted contrast agent.

Development of improved MR techniques may enhance the sensitivity of detection. Hyperpolarization of nuclear spins through dynamic nuclear polarization (DNP) has recently attracted considerable attention for increasing the signal-to-noise ratio in an NMR experiment by several orders of magnitude (Ragavan et al., 2011). However, application of this technique to larger molecules has so far proven challenging. Recently, a full length protein was hyperpolarized at low temperature and dissolved for NMR signal acquisition in the liquid state in mixtures of organic solvent and water. Signal enhancements of 300-2000 are obtained in partially deuterated polypeptide when hyperpolarized on 13C and of 30-180 when hyperpolarized on 1H (Ragavan et al., 2011). Additionally, low-field (1 T) compact benchtop MRI systems (ASPECT, IconBruker) are ideally suited to take advantage of the higher relaxivity of Gd-based contrast agents at low magnetic fields.

Although MRI-based single cell detection with the use of iron oxides has been reported, in general, much higher doses are needed as compared to for example the nuclear imaging techniques (Leuschner et al., 2011). Moreover the effect of covalent binding of peptides/lipids to Gd on the pharmacokinetics and biodistribution of the various contrast agent ingredients is uncertain. This complicates rapid approval of Gd-based MR contrast agents and its carriers for human application by the Food and Drug Administration (FDA (USA)) and European Medicines Agency (EMEA (Europe)), because of the concerns about retention in the body and toxicity. Issues are, amongst others, the unknown metabolic fate of the carrier material in the body, transmetallation of $\mathrm{Gd}^{3+}$ with native metal-ions in the body (Hak et al., 2009), and worries about Gd-induced nephrogenic systemic fibrosis (Pedersen, 2007). In this respect, nanocrystal HDL-like particles with iron oxide cores (Cormode et al., 2008; Mulder Acc Chem Res 2009; Skajaa et al., 2011) are very promising MR contrast agent candidates for clinical application because they seem to avoid most of these toxicity concerns. Figure 4 shows a schematic depiction of a nanocrystal HDL-like nanoparticle and summarizes some results achieved with it (Skajaa et al., 2011). 

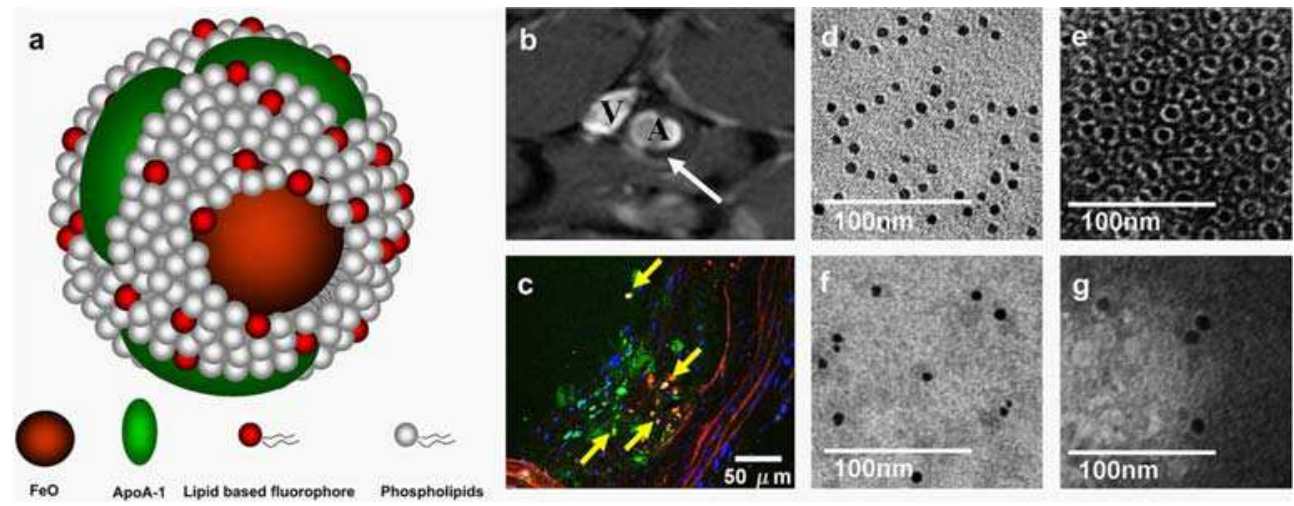

Fig. 4. Nanocrystal HDL with FeO core. Schematic depiction of FeO-HDL (a). (b) In vivo T2*weighted $(\mathrm{TR}=10 \mathrm{~ms}, \mathrm{TE}=4 \mathrm{~ms}) \mathrm{MR}$ image of abdominal region of an apoE- $/$ - mouse, $24 \mathrm{~h}$ post-injection of FeO-HDL. The white arrow denotes the black rim (black spot) in the aortic wall observed after FeO-HDL administration. (A, aorta, $\mathrm{V}$, inferior cava vein). (c) Ex vivo confocal laser microscopy of excised aorta section. Nuclei are shown in blue via DAPI staining, FeO-HDL in red (rhodamine), green color marks macrophages, stained with Alexa 647-CD68 and yellow marks co-localization of FeO-HDL and macrophages. (d) In vitro TEM images of FeO-HDL in buffer. (e) In vitro negative staining TEM image of FeO-HDL, showing that each iron oxide $(\mathrm{IO})$ particle is coated with a single monolayer of phospholipids. ( $f, g$ ) TEM and negative staining TEM of blood samples 5 min after the administration of FeO-HDL revealed individually dispersed particles, i.e. no aggregation and that the lipid coating is intact. Printed with permission from (Skajaa et al., 2011).

The use of frequency-selective paraCEST agents or perfluorocarbon nanoparticles in principle permits imaging of various target species simultaneously. Although in vitro proof of principle has been provided, in vivo application has been limited so far. Problems for paraCEST agents are related to low sensitivity and susceptibility artifacts, whereas ${ }^{19} \mathrm{~F}$ imaging also suffers from relatively low sensitivity. Concerning clinical translation, the iron oxides are most promising, since they enable the most sensitive detection with MRI while toxicity is low. The larger iron oxides provide sensitive hypointense contrast on $\mathrm{T}_{2}$-weighted images, whereas small iron oxides $(\sim 5 \mathrm{~nm})$ can also be used for $\mathrm{T}_{1}$-weighted imaging with hyperintense contrast (Taboada et al., 2007).

The application of both diagnostic and therapeutic MR agents for monitoring of drug delivery and therapeutic responses is very promising. Gd-containing liposome-encapsulated prednisolone phosphate was injected in atherosclerotic rabbits and delivery at the ballooninjured aorta was imaged with MRI (Lobatto et al., 2010). The therapeutic anti-inflammatory and anti-angiogenic effects of the glucocorticoid were monitored with DCE MRI (Lobatto et al., 2010). Another study employed paramagnetic av $\beta 3$-targeted fumagillin-loaded perfluorocarbon nanoparticles, releasing fumagillin via "contact facilitated drug delivery" (only upon ligand-directed binding) (Winter et al., 2006). These nanoparticles resulted after 1 week in a significant reduction in degree and spatial distribution of MR enhancement. This effect was not observed when no drug or non-targeted fumagillin-loaded nanoparticles 
were administered (Winter et al., 2006), thus providing evidence for the specific therapeutic effect of the targeted, drug-loaded nanoparticles.

\section{Clinical application}

In patient studies iron oxide particles and Gadofluorine $M$ have already been successfully applied for MRI of inflammation. The use of MRI with these particles combined with MRI assessment of cardiovascular function and myocardial tagging in selected patient populations with specific co-morbidity that increases risk for atherosclerotic disease may further stratify cardiovascular risk groups. Clinical application of self-assembling Gd-based molecular contrast agents is difficult due to the large amounts needed for detection and toxicity issues, especially in patients with kidney disease. Molecular targeted iron oxide nanoparticles conjugated to small peptides, recognized by phage display have lower immunogenicity when compared to full antibodies but toxicity may still hamper clinical application. Into this respect, the use of synthetic (ant)agonists or peptidomimetics for conjugation to MR visible nanoparticles combined with MRI of plaque targets in selected patient groups is anticipated to be more successful. Clinical application of perfluorocarbon nanoparticles for imaging of intravascular targets (endothelial cell markers and thrombus/activated platelets) employing the zero-background ${ }^{19} \mathrm{~F}$ signal is attractive. The safety of fluorine and the high payload of ${ }^{19} \mathrm{~F}$ which counterbalances low sensitivity of ${ }^{19} \mathrm{~F}$ MRI, make these perfluorocarbon nanoparticles (without Gd) useful contrast agents with clinical potential for targeted imaging of intravascular targets. However, first the pharmokinetic profiling information obtained in rabbits (Neubauer et al., 2008) needs to be expanded and should be obtained in patients. Activatable Gd- or iron oxide-based contrast agents sensing plaque enzyme activity may be used for detection of enzymes available at $\mathrm{nM}$ concentrations owing to enhanced relaxivity related to oligomerization of substrates or coupling of them to proteins (Tu et al., 2011). This approach is interesting in the scope of clinical application because it measures activity instead of presence of enzymes and lower toxicity is anticipated because lower Gd (or iron oxide) concentrations are needed for a certain degree of enhancement. The endogenous nature of the lipid coat of FeO-HDL-like nanoparticles, the easy incorporation of natural or synthetic lipids for increased accumulation in plaque macrophages, and the low toxicity of $\mathrm{FeO}$ makes these nanoparticles an attractive contrast agent for clinical MRI of atherosclerotic plaque. Clinical application of a specific molecular MRI method will also depend on costs of the contrast agent for a specific target of interest, the versatility of that agent and the contribution of this MRI approach to clinical decision making.

\section{Conclusion}

A number of strategies for cellular and molecular MRI of atherosclerosis were successfully developed. Proof of concept clinical application was already established for imaging of macrophages using non-targeted iron oxides and at a more immature stage for the fibrin-targeted small-molecule peptides conjugated to Gd-DTPA. Future studies will have to clarify whether the targeted contrast agents have diagnostic or prognostic added value in the evaluation of atherosclerotic plaque progression/rupture in humans. Promising new developments include activatable contrast agents, which are able to report on enzyme activity, perfluorocarbon nanoparticles exploiting the zero-background ${ }^{19} \mathrm{~F}$ signal, as well as 
the use of modified MRI-visible endogenous nanoparticles, such as HDL and LDL, for imaging of atherosclerosis and specific plaque components.

\section{Acknowledgements}

This work was supported by the European Network of Excellence Diagnostic Molecular Imaging (DIMI, LSHB-CT-2005-512146), the Integrated European Union Project Targeted Delivery of Nanomedicine (MEDITRANS, FP6-2004-NMP-NI-4/IP 026668-2), and the Netherlands Heart Foundation Grant (NHF, 2006T106 and 2003B249).

\section{References}

Akhtar, A., Schneider, J., Chapman, S., Jefferson, A., Digby, J., Mankia, K., Chen, Y., McAteer, M., Wood, K., \& Choudhury, R. (2010). In vivo quantification of VCAM-1 expression in renal ischemia reperfusion injury using non-invasive magnetic resonance molecular imaging. PLoS One, Vol.5, No.9, (September 2010), pp. e12800, ISSN 1932-6203

Alsaid, H., De Souza, G., Bourdillon, M., Chaubet, F., Sulaiman, A., Desbleds-Mansard, C., Chaabane, L., Zahir, C., Lancelot, E., Rousseaux, O., Corot, C., Douek, P., Briguet, A., Letourneur, D., \& Canet-Soulas E. (2009). Biomimetic MRI contrast agent for imaging of inflammation in atherosclerotic plaque of ApoE-/- mice: a pilot study. Investigative Radiology, Vol.44, No.3, (March 2009), pp. 151-158, ISSN 1536-0210

Amirbekian, V., Lipinski, M., Briley-Saebo, K., Amirbekian, S., Aguinaldo, J., Weinreb, D., Vucic, E., Frias, J., Hyafil, F., Mani, V., Fisher, E., \& Fayad, Z. (2007). Detecting and assessing macrophages in vivo to evaluate atherosclerosis noninvasively using molecular MRI. Proceedings of the National Academy of Sciences of the United States of America, Vol.104, No.3, (January 2007), pp. 961-966, ISSN 0027-8424

Anderson, S., Rader, R., Westlin, W., Null, C., Jackson, D., Lanza, G., Wickline, S., \& Kotyk, J. (2000). Magnetic resonance contrast enhancement of neovasculature with alpha(v)beta(3)-targeted nanoparticles. Magnetic Resonance in Medicine, Vol.44, No.3, (September 2000), pp. 433-439, ISSN 0740-3194

Barkhausen, J., Ebert, W., Heyer, C., Debatin, F., \& Weinmann H. (2003). Detection of atherosclerotic plaque with Gadofluorine-enhanced magnetic resonance imaging. Circulation, Vol.108, No.5, (August 2003), pp. 605-609, ISSN 1524-4539

Brennan, M., Reddy, A., Tang, W., Wu, Y., Brennan, D., Hsu, A., Mann, S., Hammer, P., \& Hazen, S. (2010). Comprehensive peroxidase-based hematologic profiling for the prediction of 1-year myocardial infarction and death. Circulation, Vol.122, No.1, (July 2010), pp. 70-79, ISSN 1524-4539

Briley-Saebo, K., Shaw, P., Mulder, W., Choi, S., Vucic, E., Aguinaldo, J., Witztum, J., Fuster, V., Tsimikas, S., \& Fayad, Z. (2008). Targeted molecular probes for imaging atherosclerotic lesions with magnetic resonance using antibodies that recognize oxidation-specific epitopes. Circulation, Vol.117, No.25, (June 2008), pp. 3206-3215, ISSN 1524-4539

Briley-Saebo, K., Cho, Y., Shaw, P., Ryu, S., Mani, V., Dickson, S., Izadmehr, E., Green, S., Fayad, Z., \& Tsimikas, S. (2011). Targeted iron oxide particles for in vivo magnetic 
resonance detection of atherosclerotic lesions with antibodies directed to oxidationspecific epitopes. Journal of the American College of Cardiology, Vol.57, No.3, (January 2011), pp. 337-347, ISNN 1558-3597

Burtea, C., Laurent, S., Lancelot, E., Ballet, S., Murariu, O., Rousseaux, O., Port, M., Vander Elst, L., Corot, C., \& Muller, R. (2009). Peptidic targeting of phosphatidylserine for the MRI detection of apoptosis in atherosclerotic plaques. Molecular Pharmaceutics, Vol.6, No.6, (November-December 2009), pp. 1903-1919, ISSN 1543-8392

Cai, K., Caruthers, S., Huang, W., Williams, T., Zhang, H., Wickline, S., Lanza, G., \& Winter, P. (2010). MR molecular imaging of aortic angiogenesis. Journal of the American College of Cardiology. Cardiovascular Imaging, Vol.3, No.8, (August 2010), pp. 824-832, ISSN 1876-7591

Cai, K., Kiefer, G., Caruthers, S., Wickline, S., Lanza, G., \& Winter, P. (2011). Quantification of water exchange kinetics for targeted PARACEST perfluorocarbon nanoparticles. NMR in Biomedicine, Epub ahead of print (July 2011), ISSN 1099-1492

Calcagno, C., Mani, V., Ramachandran, S., \& Fayad, Z. (2010). Dynamic contrast enhanced (DCE) magnetic resonance imaging (MRI) of atherosclerotic plaque angiogenesis. Angiogenesis, Vol.13, No.2, (June 2010), pp. 87-99, ISSN 1573-7209

Calfon, M., Vinegoni, C., Ntziachristos, V., \& Jaffer, F. (2010). Intravascular near-infrared fluorescence molecular imaging of atherosclerosis: toward coronary arterial visualization of biologically high-risk plaques. Journal of Biomedical Optics, Vol.15, No.1. (January-February 2010), pp. 011107, ISSN 1560-2281

Chen, I., \& Wu, J. (2011). Cardiovascular molecular imaging: focus on clinical translation. Circulation, Vol.123, No.4, (February 2011), pp. 425-443, ISSN 1524-4539

Chen, J., Pham, W., Weissleder, R., \& Bogdanov, A. (2004). Human myeloperoxidase: a potential target for molecular MR imaging in atherosclerosis. Magnetic Resonance in Medicine, Vol.52, No.5, (November 2004), pp. 1021-1028, ISSN 0740-3194

Chen, W., Vucic, E., Leupold, E., Mulder, W., Cormode, D., Briley-Saebo, K., Barazza, A., Fisher, E., Dathe, M., \& Fayad Z. (2008). Incorporation of an apoE-derived lipopeptide in high-density lipoprotein MRI contrast agents for enhanced imaging of macrophages in atherosclerosis. Contrast Media \& Molecular Imaging, Vol.3, No.6, (November-December 2008), pp. 233-242, ISSN 1555-4317

Cheng, C., Tempel, D., Van Haperen, R., Van der Baan, A., Grosveld, F., Daemen, M., Krams, R., \& De Crom, R. (2006). Atherosclerotic lesion size and vulnerability are determined by patterns of fluid shear stress. Circulation, Vol.113, No.23, (June 2006), pp. 2744-2753, ISSN 1524-4539

Cormode, D., Briley-Saebo, K., Mulder, W., Aguinaldo, J., Barazza, A., Ma, Y., Fisher, E., \& Fayad, Z. (2008). An ApoA-I mimetic peptide high-density-lipoprotein-based MRI contrast agent for atherosclerotic plaque composition detection. Small, Vol.4, No.9, (September 2008), pp. 1437-1444, ISSN 1613-6829

Cormode, D., Skajaa, T., Van Schooneveld, M., Koole, R., Jarzyna, P., Lobatto, M., Calcagno, C., Barazza, A., Gordon, R., Zanzonico, P., Fisher, E., Fayad, Z., \& Mulder W. (November 2008). Nanocrystal core high-density lipoproteins: a multimodality contrast agent platform. Nano Letters, Vol.8, No.11, (November 2008), pp. 3715-23, ISSN 1530-6984 
Cormode, D., Chandrasekar, R., Delshad, A., Briley-Saebo, K., Calcagno, C., Barazza, A., Mulder, W., Fisher, E., Fayad, Z. (2009). Comparison of synthetic high density lipoprotein (HDL) contrast agents for MR imaging of atherosclerosis. Bioconjugate Chemistry, Vol.20, No. 5, (May 2009), pp. 937-943, ISSN 1520-4812

Dunmore, B., McCarthy, M., Naylor, A., \& Brindle, N. (2007). Carotid plaque instability and ischemic symptoms are linked to immaturity of microvessels within plaques. Journal of Vascular Surgery, Vol.45, No.1, (January 2007), pp. 155-159, ISSN 07415214

Falk, E., Shah, P., \& Fuster, V. (1995). Coronary plaque disruption. Circulation, Vol.92, No.3, (August 1995), pp. 657-671, ISSN 0009-7322

Frias, J., Williams, K., Fisher, E., \& Fayad, Z. (2004). Recombinant HDL-like nanoparticles: a specific contrast agent for MRI of atherosclerotic plaques. Journal of the American Chemical Society, Vol.126, No.50, (December 2004), pp. 16316-16317, ISSN 0002-7863

Frias, J., Ma, Y., Williams, K., Fayad, Z., \& Fisher, E. (2006). Properties of a versatile nanoparticle platform contrast agent to image and characterize atherosclerotic plaques by magnetic resonance imaging. Nano Letters, Vol.6, No.10, (October 2006), pp. 2220-2224, ISSN 1530-6984

Galis, Z., \& Khatri, J. (2002). Matrix metalloproteinases in vascular remodeling and atherogenesis: the good, the bad, and the ugly. Circulation Research, Vol.90, No.3, (February 2002), pp. 251-262, ISSN 1524-4571

Gerke, V., \& Moss, S. (2002). Annexins: from structure to function. Physiological Reviews, Vol.82, No.2, (April 2002), pp. 331-371, ISSN 0031-9333

Hak, S., Sanders, H., Agrawal, P., Langereis, S., Grüll, H., Keizer, H., Arena, F., Terreno, E., Strijkers, G., \& Nicolay, K. (2009). A high relaxivity Gd(III)DOTA-DSPE-based liposomal contrast agent for magnetic resonance imaging. European Journal of Pharmaceuticsand Biopharmaceutics, Vol.72, No.2, (June 2009), pp. 397-404, ISSN 18733441

Hemdahl, A., Gabrielsen, A., Zhu, C., Eriksson, P., Hedin, U., Kastrup, J., Thorén, P., \& Hansson, G. (2006). Expression of neutrophil gelatinase-associated lipocalin in atherosclerosis and myocardial infarction. Arteriosclerosis, Thrombosis, and Vascular Biology, Vol.26, No.1, (January 2006), pp. 136-142, ISSN 1524-4636

Hofstra, L., Liem, I., Dumont, E., Boersma, H., van Heerde, W., Doevendans, P., De Muinck, E., Wellens, H., Kemerink, G., Reutelingsperger, C., \& Heidendal, G. (2000). Visualisation of cell death in vivo in patients with acute myocardial infarction. Lancet, Vol.356, No.9225, (July 2000), pp. 209-212, ISSN 0140-6736

Hyafil, F., Cornily, J., Feig, J., Gordon, R., Vucic E., Amirbekian, V., Fisher, E., Fuster, V., Feldman, L., \& Fayad, Z. (2007). Noninvasive detection of macrophages using a nanoparticulate contrast agent for computed tomography. Nature Medicine, Vol.13, No.5, (May 2007), pp. 636-641, ISSN 1078-8956

Ide, M., Kuwamura, M., Kotani, T., Sawamoto, O., \& Yamate, J. (2005). Effects of gadolinium chloride $(\mathrm{GdCl}(3))$ on the appearance of macrophage populations and fibrogenesis in thioacetamide-induced rat hepatic lesions. Journal of Comparative Pathology, Vol.133, No.2-3, (August-October 2005), pp. 92-102, ISSN 0021-9975 
Iga, A., Robertson, J., Winslet, M., \& Seifalian, A. (2007). Clinical potential of quantum dots. Journal of Biomedicine \& Biotechnology, Vol.2007, No.10, (2007), pp. 1-10, ISSN 11107243

Johansson, L., Bjornerud, A., Ahlstrom, H., Ladd, D., \& Fujii, D. (2001). A targeted contrast agent for magnetic resonance imaging of thrombus: implications of spatial resolution. Journal of Magnetic Resonance Imaging, Vol.13, No.4, (April 2001), pp. 615618, ISSN 1053-1807

Kamat, M., El-Boubbou, K., Zhu, D., Lansdell, T., Lu, X., Li, W., \& Huang, X. (2010). Hyaluronic acid immobilized magnetic nanoparticles for active targeting and imaging of macrophages. Bioconjugate Chemistry, Vol.21, No.11, (November 2010), pp. 2128-2135, ISSN 1520-4812

Kelly, K., Allport, J., Tsourkas, A., Shinde-Patil, V., Josephson, L., Weissleder, R. (2005). Detection of vascular adhesion molecule-1 expression using a novel multimodal nanoparticle. Circulation Research, Vol.96, No.3, (February 2005), pp. 327-336, ISSN 1524-4571

Kolodgie, F., Petrov, A., Virmani, R., Narula, N., Verjans, J., Weber, D., Hartung, D., Steinmetz, N., Vanderheyden, J., Vannan, M., Gold, H., Reutelingsperger, C., Hofstra, L., \& Narula, J. (2003). Targeting of apoptotic macrophages and experimental atheroma with radiolabeled annexin $\mathrm{V}$ : a technique with potential for noninvasive imaging of vulnerable plaque. Circulation, Vol.108, No.25, (December 2003), pp. 3134-3139, ISSN 1524-4539

Lancelot, E., Amirbekian, V., Brigger, I., Raynaud, J., Ballet, S., David, C., Rousseaux, O., Le Greneur, S., Port, M., Lijnen, H., Bruneval, P., Michel, J., Ouimet, T., Roques, B., Amirbekian, S., Hyafil, F., Vucic, E., Aguinaldo, J., Corot, C., \& Fayad, Z. (2008). Evaluation of matrix metalloproteinases in atherosclerosis using a novel noninvasive imaging approach. Arteriosclerosis, Thrombosis, and Vascular Biology, Vol.28, No.3, (March 2008), pp. 425-432, ISSN 1524-4636

Leuschner, F., \& Nahrendorf, M. (2011). Molecular imaging of coronary atherosclerosis and myocardial infarction: considerations for the bench and perspectives for the clinic. Circulation Research, Vol.108, No.5, (March 2011), pp. 593-606, ISSN 1524-4571

Li, D., Patel, A., Klibanov, A., Kramer, C., Ruiz, M., Kang, B., Mehta, J., Beller, G., Glover, D., \& Meyer C. (2010). Molecular imaging of atherosclerotic plaques targeted to oxidized LDL receptor LOX-1 by SPECT/CT and magnetic resonance. Circulation. Cardiovascular Imaging, Vol.3, No.4, (July 2010), pp. 464-472, ISSN 1942-0080

Libby, P. (2002). Inflammtion in atherosclerosis. Nature, Vol.420, No.6917, (December 2002), pp. 868-874, ISSN 0028-0836

Lipinski, M., Frias, J., Amirbekian, V., Briley-Saebo, K., Mani, V., Samber, D., Abbate, A., Aguinaldo, J., Massey, D., Fuster, V., Vetrovec, G., \& Fayad, Z. (2009). Macrophagespecific lipid-based nanoparticles improve cardiac magnetic resonance detection and characterization of human atherosclerosis. Journal of the American College of Cardiology. Cardiovascular Imaging, Vol.2, No.5, (May 2009), pp. 637-647, ISSN 18767591

Lobatto, M., Fayad, Z., Silvera, S., Vucic, E., Calcagno, C., Mani, V., Dickson, S., Nicolay, K., Banciu, M., Schiffelers, R., Metselaar, J., Van Bloois, L., Wu, H., Fallon, J., Rudd, J., Fuster, V., Fisher, E., Storm, G., \& Mulder, W. (2010). Multimodal clinical imaging 
to longitudinally assess a nanomedical anti-inflammatory treatment in experimental atherosclerosis. Molecular Pharmaceutics, Vol.7, No.6, (December 2010), pp. 2020-2029, ISSN 1543-8392

Maiseyeu, A., Mihai, G., Kampfrath, T., Simonetti, O., Sen, C., Roy, S., Rajagopalan, S., \& Parthasarathy, S. (2009). Gadolinium-containing phosphatidylserine liposomes for molecular imaging of atherosclerosis. Journal of Lipid Research, Vol.50, No.11, (November 2009), pp. 2157-2163, ISSN 0022-2275

Makowski, M., Wiethoff, A., Blume, U., Cuello, F., Warley, A., Jansen, C., Nagel, E., Razavi, R., Onthank, D., Cesati, R., Marber, M., Schaeffter, T., Smith, A., Robinson, S., \& Botnar, R. (2011). Assessment of atherosclerotic plaque burden with an elastinspecific magnetic resonance contrast agent. Nature Medicine, Vol.17, No.3, (March 2011), pp. 383-388, ISSN 1546-170X

Massoud, T., \& Gambhir, S. (2003). Molecular imaging in living subjects: seeing fundamental biological processes in a new light. Genes $\mathcal{E}$ Development, Vol.17, No.5, (March 2003), pp. 545-580, ISSN 0890-9369Lusis, A. (2000). Atherosclerosis. Nature, Vol.407, No.6801, (September 2000), pp. 233-241, ISSN 0028-0836

McAteer, M., Akhtar, A., Von zur Muhlen, C., \& Choudhury, R. (2010). An approach to molecular imaging of atherosclerosis, thrombosis, and vascular inflammation using microparticles of iron oxide. Atherosclerosis, Vol.209, No.1, (March 2010), pp. 18-27, ISSN 1879-1484.

Meding, J., Urich, M., Licha, K., Reinhardt, M., Misselwitz, B., Fayad, Z., \& Weinmann H. (2007). Magnetic resonance imaging of atherosclerosis by targeting extracellular matrix deposition with Gadofluorine M. Contrast Media \& Molecular Imaging, Vol.2, No.3, (May-June 2007), pp. 120-129, ISSN 1555-4317

Miserus, R., Herias, M., Prinzen, L., Lobbes, M., Van Suylen, R., Dirksen, A., Hackeng, T., Heemskerk, J.,Van Engelshoven, J., Daemen, M., Van Zandvoort, M., Heeneman, S., \& Kooi, M. (2009). Molecular MRI of early thrombus formation using a bimodal alpha2-antiplasmin-based contrast agent. Journal of the American College of Cardiology. Cardiovascular Imaging, Vol.2, No.8, (August 2009), pp. 987-996, ISSN 1876-7591

Morawski, A., Winter, P., Yu, X., Fuhrhop, R., Scott, M., Hockett, F., Robertson, J., Gaffney, P., Lanza, G., Wickline, S. (2004). Quantitative "magnetic resonance immunohistochemistry" with ligand-targeted (19)F nanoparticles. Magnetic Resonance in Medicine, Vol.52, No.6, (December 2004), pp. 1255-1262, ISSN 0740-3194

Mulder, W., Douma, K., Koning, G., Van Zandvoort, M., Lutgens, E., Daemen, M., Nicolay, K., \& Strijkers, G. (2006). Liposome-enhanced MRI of neointimal lesions in the ApoE-KO mouse. Magnetic Resonance in Medicine, Vol.55, No.5, (May 2006), pp. 1170-1174, ISSN 0740-3194

Mulder, W., Strijkers, G., Vucic, E., Cormode, D., Nicolay, K., \& Fayad, Z. (2007). Magnetic resonance molecular imaging contrast agents and their application in atherosclerosis. Topics in Magnetic Resonance Imaging, Vol.18, No.5, (October 2007a), pp. 409-417, ISSN 0899-3459

Mulder W., Strijkers, G., Briley-Saebo, K., Frias, J., Aguinaldo, J., Vucic, E., Amirbekian, V., Tang, C., Chin, P., Nicolay, K., \& Fayad, Z. (2007b). Molecular imaging of 
macrophages in atherosclerotic plaques using bimodal PEG-micelles. Magnetic Resonance in Medicine, Vol.58, No.6, (December 2007), pp. 1164-1170, ISSN 0740-3194

Mulder W., Strijkers, G., Van Tilborg, G., Cormode, D., Fayad, Z., \& Nicolay K. (2009). Nanoparticulate assemblies of amphiphiles and diagnostically active materials for multimodality imaging. Accounts of Chemical Research, Vol.42, No.7, (July 2009), pp. 904-914, ISSN 1520-4898

Naghavi, M., Libby, P., Falk, E., Casscells, S., Litovsky, S., Rumberger, J., Badimon, J., Stefanadis, C., Moreno, P., Pasterkamp, G., Fayad, Z., Stone, P., Waxman, S., Raggi, P., Madjid, M., Zarrabi, A., Burke, A., Yuan, C., Fitzgerald, P., Siscovick, D., de Korte, C., Aikawa, M., Airaksinen, K., Assmann, G., Becker, C., Chesebro, J., Farb, A., Galis, Z., Jackson, C., Jang, I., Koenig, W., Lodder, R., March, K., Demirovic, J., Navab, M., Priori, S., Rekhter, M., Bahr, R., Grundy, S., Mehran, R., Colombo, A., Boerwinkle, E., Ballantyne, C., Insull, W. Jr, Schwartz, R., Vogel, R., Serruys, P., Hansson, G., Faxon, D., Kaul, S., Drexler, H., Greenland, P., Muller, J., Virmani, R., Ridker, P., Zipes, D., Shah, P., \& Willerson, J. (2003a). From vulnerable plaque to vulnerable patient: a call for new definitions and risk assessment strategies: Part I. Circulation, Vol.108, No.14, (October 2003), pp. 1664-1672, ISSN 1524-4539

Naghavi, M., Libby, P., Falk, E., Casscells, S., Litovsky, S., Rumberger, J., Badimon, J., Stefanadis, C., Moreno, P., Pasterkamp, G., Fayad, Z., Stone, P., Waxman, S., Raggi, P., Madjid, M., Zarrabi, A., Burke, A., Yuan, C., Fitzgerald, P., Siscovick, D., de Korte, C., Aikawa, M., Airaksinen, K., Assmann, G., Becker, C., Chesebro, J., Farb, A., Galis, Z., Jackson, C., Jang, I., Koenig, W., Lodder, R., March, K., Demirovic, J., Navab, M., Priori, S., Rekhter, M., Bahr, R., Grundy, S., Mehran, R., Colombo, A., Boerwinkle, E., Ballantyne, C., Insull, W. Jr, Schwartz, R., Vogel, R., Serruys, P., Hansson, G., Faxon, D., Kaul, S., Drexler, H., Greenland, P., Muller, J., Virmani, R., Ridker, P., Zipes, D., Shah, P., \& Willerson, J. (2003b). From vulnerable plaque to vulnerable patient: a call for new definitions and risk assessment strategies: Part II. Circulation, Vol.108, No.15, (October 2003), pp. 1772-1778, ISSN 1524-4539

Nahrendorf, M., Jaffer, F., Kelly, K., Sosnovik, D., Aikawa, E., Libby, P., \& Weissleder, R. (2006). Noninvasive vascular cell adhesion molecule-1 imaging identifies inflammatory activation of cells in atherosclerosis. Circulation, Vol.114, No.14, (October 2006), pp. 1504-1511, ISSN 1524-4539

Neubauer, A., Sim, H.,Winter, P., Caruthers, S., Williams, T., Robertson, J., Sept, D., Lanza, G., \& Wickline, S. (2008). Nanoparticle pharmacokinetic profiling in vivo using magnetic resonance imaging. Magnetic Resonance in Medicine, Vol.60, No.6, (December 2008), pp. 1353-1361, ISSN 1522-2594

Pedersen, M. (2007). Safety update on the possible causal relationship between gadoliniumcontaining MRI agents and nephrogenic systemic fibrosis. Journal of Magnetic Resonance Imaging, Vol.25, No.5, (May 2007), pp. 881-883, ISSN 1053-1807

Ragavan, M., Chen, H., Sekar, G., \& Hilty, C. (2011). Solution NMR of polypeptides hyperpolarized by dynamic nuclear polarization. Analytical Chemistry, Vol.83, No.15, (August 2011), pp. 6054-6059, ISSN 1520-6882

Ronald, J., Chen, J., Chen, Y., Hamilton, A., Rodriguez, E., Reynolds, F., Hegele, R., Rogers, K., Querol, M., Bogdanov, A., Weissleder, R., \& Rutt, B. (2009). Enzyme-sensitive magnetic resonance imaging targeting myeloperoxidase identifies active 
inflammation in experimental rabbit atherosclerotic plaques. Circulation, Vol.120, No.7, (August 2009), pp. 592-599, ISSN 1524-4539

Ross, R. (1999). Atherosclerosis - an inflammatory disease. New England Journal of Medicine, Vol.340, No.2, (January 1999), pp. 115-126, ISSN 0028-4793

Rudd, J., Myers, K., Bansilal, S., Machac, J., Rafique, A., Farkouh, M., Fuster, V., \& Fayad, Z. (2007). (18)Fluorodeoxyglucose positron emission tomography imaging of atherosclerotic plaque inflammation is highly reproducible: implications for atherosclerosis therapy trials. Journal of the American College of Cardiology, Vol.50, No.9, August 2007), pp. 892-896, ISSN 1558-3597

Sanders, H., Strijkers, G., Mulder, W., Huinink, H., Erich, S., Adan, O., Sommerdijk, N., Merkx, M., \& Nicolay, K. (2009). Morphology, binding behavior and MR-properties of paramagnetic collagen-binding liposomes. Contrast Media \& Molecular Imaging, Vol.4, No.2, (March-April 2009), pp. 81-88, ISSN 1555-4317

Schafers, M., Schober, O., \& Hermann, S. (2010). Matrix-metalloproteinases as imaging targets for inflammatory activity in atherosclerotic plaques. Journal of Nuclear Medicine, Vol.51, No.5, (May 2010), pp. 663-666, ISSN 1535-5667

Schmitz, S., Taupitz, M., Wagner, S., Wolf, K., Beyersdorff, D., \& Hamm, B. (2001). Magnetic resonance imaging of atherosclerotic plaques using superparamagnetic iron oxide particles. Journal of Magnetic Resonance Imaging, Vol.14, No.4, (October 2001), pp. 355-361, ISSN 1053-1807

Schmitz, S. (2003). [Iron-oxide-enhanced MR imaging of inflammatory atherosclerotic lesions: overview of experimental and initial clinical results]. Rofo, Vol.175, No.4, (April 2003), pp. 469-476, ISSN 1438-9029

Sirol, M., Moreno, P., Purushothaman, K., Vucic, E., Amirbekian, V., Weinmann, H., Muntner, P., Fuster, V., \& Fayad, Z. (2009). Increased neovascularization in advanced lipid-rich atherosclerotic lesions detected by gadofluorine-M-enhanced MRI: implications for plaque vulnerability. Circulation. Cardiovascular Imaging, Vol.2, No.5, (September 2009), pp. 391-396, ISSN 1942-0080

Skajaa, T., Cormode, D., Falk, E., Mulder, W., Fisher, E., \& Fayad, Z. (2010). High-density lipoprotein-based contrast agents for multimodal imaging of atherosclerosis. Arteriosclerosis, Thrombosis, and Vascular Biology, Vol.30, No.2, (February 2010), pp. 169-176, ISSN 1524-4636

Skajaa, T., Cormode, D., Jarzyna, P., Delshad, A., Blachford, C., Barazza, A., Fisher, E., Gordon, R., Fayad, Z., \& Mulder, W. (2011). The biological properties of iron oxide core high-density lipoprotein in experimental atherosclerosis. Biomaterials, Vol.32, No.1, (January 2011), pp. 206-213, ISSN 1878-5905

Sluimer, J., \& Daemen, M. (2009). Novel concepts in atherogenesis: angiogenesis and hypoxia in atherosclerosis. Journal of Pathology, Vol.218, No.1, (May 2009), pp. 7-29, ISSN 1096-9896

Spuentrup, E., Botnar, R., Wiethoff, A., Ibrahim, T., Kelle, S., Katoh, M., Ozgun, M., Nagel, E., Vymazal, J., Graham, P., Günther, R., \& Maintz, D. (2008). MR imaging of thrombi using EP-2104R, a fibrin-specific contrast agent: initial results in patients. European Radiology, Vol.18, No.9, (September 2008), pp. 1995-2005, ISSN 0938-7994

Stary, H., Chandler, A., Dinsmore, R., Fuster, V., Glagov, S., Insull, W. Jr, Rosenfeld, M., Schwartz, C., Wagner, W., \& Wissler, R. (1995). A definition of advanced types of 
atherosclerotic lesions and a histological classification of atherosclerosis. A report from the Committee on Vascular Lesions of the Council on Arteriosclerosis, American Heart Association. Arteriosclerosis, Thrombosis, and Vascular Biology, Vol.15, No.9, (September 1995), pp. 1512-1531, ISSN 1079-5642

Steffens, S., Veillard, N., Arnaud, C., Pelli, G., Burger, F., Staub, C., Karsak, M., Zimmer, A., Frossard, J., \& Mach, F. (2005). Low dose oral cannabinoid therapy reduces progression of atherosclerosis in mice. Nature, Vol.434, No.7034, (April 2005), pp. 782-786, ISSN 1476-4687

Ta, H., Prabhu, S., Leitner, E., Jia, F., Von Elverfeldt, D., Jackson, K., Heidt, T., Nair, A., Pearce, H., Von Zur Muhlen, C., Wang, X., Peter, K., \& Hagemeyer, C. (2011). Enzymatic Single-Chain Antibody Tagging: A Universal Approach to Targeted Molecular Imaging and Cell Homing in Cardiovascular Disease. Circulation Research, Vol.109, No.4, (August 2011), pp. 365-373, ISSN 1524-4571

Taboada, E., Rodriguez, E., Roig, A., Oró, J., Roch, A., Muller, R. (2007). Relaxometric and magnetic characterization of ultrasmall iron oxide nanoparticles with high magnetization. Evaluation as potential T1 magnetic resonance imaging contrast agents for molecular imaging. Langmuir, Vol.23, No.8, (April 2007), pp. 4583-4588, ISSN 0743-7463

Takaya, N., Yuan, C., Chu, B., Saam, T., Polissar, N., Jarvik, G., Isaac, C., McDonough, J., Natiello, C., Small, R., Ferguson, M., \& Hatsukami, T. (2005). Presence of intraplaque hemorrhage stimulates progression of carotid atherosclerotic plaques: a high-resolution magnetic resonance imaging study. Circulation, Vol.111, No.21, (May 2005), pp. 2768-2775, ISSN 1524-4539

Tang, T., Howarth, S., Miller, S., Graves, M., Patterson, A., U-King-Im, J., Li, Z., Walsh, S., Brown, A., Kirkpatrick, P., Warburton, E., Hayes, P., Varty, K., Boyle, J., Gaunt, M., Zalewski, A., \& Gillard, J. (2009). The ATHEROMA (Atorvastatin Therapy: Effects on Reduction of Macrophage Activity) Study. Evaluation using ultrasmall superparamagnetic iron oxide-enhanced magnetic resonance imaging in carotid disease. Journal of the American College of Cardiology, Vol.53, No.22, (June 2009), pp. 2039-2050, ISSN 1558-3597

Te Boekhorst, B., Bovens, S., Nederhoff, M., Van de Kolk, K., Cramer, M., Van Oosterhout, M., Ten Hove, M., Doevendans, P., Pasterkamp, G., \& Van Echteld, C. (2010a). Negative MR contrast caused by USPIO uptake in lymph nodes may lead to false positive observations with in vivo visualization of murine atherosclerotic plaque. Atherosclerosis, Vol.210, No.1, (May 2010), pp. 122-129, ISSN 1879-1484

Te Boekhorst, B., Bovens, S., Van de Kolk, C., Cramer, M., Doevendans, P., Ten Hove, M., Van der Weerd, L., Poelmann, R., Strijkers, G., Pasterkamp, G., \& Van Echteld, C. (2010b). The time window of MRI of murine atherosclerotic plaques after administration of CB2 receptor targeted micelles: inter-scan variability and relation between plaque signal intensity increase and gadolinium content of inversion recovery prepared versus non-prepared fast spin echo. NMR in Biomedicine, Vol.23, No.8, (October 2010), pp. 939-951, ISSN 1099-1492

Te Boekhorst, B., Bovens, S., Rodrigues-Feo, J., Sanders, H., Van de Kolk, C., De Kroon, A., Cramer, M., Doevendans, P., Ten Hove, M., Pasterkamp, G., \& Van Echteld, C. (2010c). Characterization and in vitro and in vivo testing of CB2-receptor- and 
NGAL-targeted paramagnetic micelles for molecular MRI of vulnerable atherosclerotic plaque. Molecular Imaging and Biology, Vol.12, No.6, (December 2010), pp. 635-651, ISSN 1860-2002

Te Boekhorst, B., Bovens, S., Hellings, W., Van der Kraak, P., Van de Kolk, K., Vink, A., Moll, F., Van Oosterhout, M., De Vries, J., Doevendans, P., Goumans, M., De Kleijn, D., Van Echteld, C., Pasterkamp, G., \& Sluijter, J. (2011). Molecular MRI of murine atherosclerotic plaque targeting NGAL: a protein associated with unstable human plaque characteristics. Cardiovascular Research, Vol.89, No.3, (February 2011), pp. 680-688, ISSN 1755-3245

Tsimikas, S., Shortal, B., Witztum, J., \& Palinski, W. (2000). In vivo uptake of radiolabeled MDA2, an oxidation-specific monoclonal antibody, provides an accurate measure of atherosclerotic lesions rich in oxidized LDL and is highly sensitive to their regression. Arteriosclerosis, Thrombosis, and Vascular Biology, Vol.20, No.3, (March 2000), pp. 689-697, ISSN 1079-5642

$\mathrm{Tu}$, C., Osborne, E., \& Louie, A. (2011). Activatable $\mathrm{T}_{1}$ and $\mathrm{T}_{2}$ magnetic resonance imaging contrast agents. Annals of Biomedical Engineering, Vol.39, No.4, (April 2011), pp. 1335-1348, ISSN 1521-6047

Van Bochove, G., Paulis, L., Segers, D., Mulder, W., Krams, R., Nicolay, K., \& Strijkers, G. (2011). Contrast enhancement by differently sized paramagnetic MRI contrast agents in mice with two phenotypes of atherosclerotic plaque. Contrast Media $\mathcal{E}$ Molecular Imaging, Vol.6, No.1, (January-February 2011), pp. 35-45, ISSN 15554317

Van Tilborg, G., Vucic, E., Strijkers, G., Cormode, D., Mani, V., Skajaa, T., Reutelingsperger, C., Fayad, Z., Mulder, W., \& Nicolay, K. (2010). Annexin A5-functionalized bimodal nanoparticles for MRI and fluorescence imaging of atherosclerotic plaques. Bioconjugate Chemistry, Vol.21, No.10, (October 2010), pp. 1794-1803, ISSN $1520-4812$

Vink, A., \& Pasterkamp, G. (2002). Atherosclerotic plaque burden, plaque vulnerability and arterial remodeling: the role of inflammation. Minerva Cardioangiologica, Vol.50, No.2, (April 2002), pp. 75-83, ISSN 0026-4725

Ward, K., Aletras, A., \& Balaban, R. (2000). A new class of contrast agents for MRI based on proton chemical exchange dependent saturation transfer (CEST). Journal of Magnetic Resonance, Vol.143, No.1, (March 2000), pp. 79-87, ISSN 1090-7807

Winter, P., Caruthers, S., Yu, X., Song, S., Chen, J., Miller, B., Bulte, J., Robertson, D., Gaffney, P., Wickline, S., \& Lanza G. (2003). Improved molecular imaging contrast agent for detection of human thrombus. Magnetic Resonance in Medicine, Vol.50, No.2, (August 2003), pp. 411-416, ISSN 0740-3194

Winter, P., Cai, K., Chen, J., Adair, C., Kiefer, G., Athey, P., Gaffney, P., Buff, C., Robertson, J., Caruthers, S., Wickline, S., \& Lanza, G. (2006). Targeted PARACEST nanoparticle contrast agent for the detection of fibrin. Magnetic Resonance in Medicine, Vol.56, No.6, (December 2006), pp. 1384-1388, ISSN 0740-3194

Winter, P., Caruthers, S., Allen, J., Cai, K., Williams, T., Lanza, G., \& Wickline, S. (2010). Molecular imaging of angiogenic therapy in peripheral vascular disease with alphanubeta3-integrin-targeted nanoparticles. Magnetic Resonance in Medicine, Vol.64, No.2, (August 2010), pp. 369-376, ISSN 1522-2594 
Yuan, C., Kerwin, W., Ferguson, M., Polissar, N., Zhang, S., Cai, J., \& Hatsukami, T. (2002). Contrast-enhanced high resolution MRI for atherosclerotic carotid artery tissue characterization. Journal of Magnetic Resonance Imaging, Vol.15, No.1, (January 2002), pp. 62-67, ISSN 1053-1807 


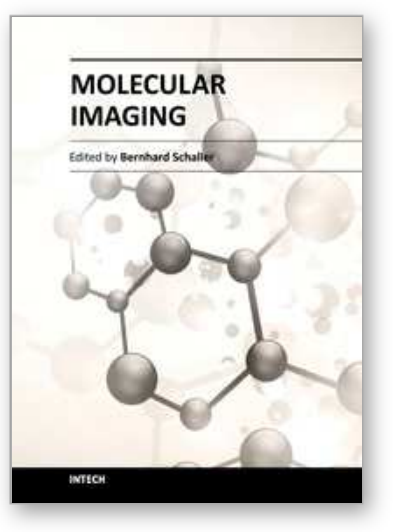

\author{
Molecular Imaging \\ Edited by Prof. Bernhard Schaller
}

ISBN 978-953-51-0359-2

Hard cover, 390 pages

Publisher InTech

Published online 16, March, 2012

Published in print edition March, 2012

The present book gives an exceptional overview of molecular imaging. Practical approach represents the red thread through the whole book, covering at the same time detailed background information that goes very deep into molecular as well as cellular level. Ideas how molecular imaging will develop in the near future present a special delicacy. This should be of special interest as the contributors are members of leading research groups from all over the world.

\title{
How to reference
}

In order to correctly reference this scholarly work, feel free to copy and paste the following:

B.C. Te Boekhorst and K. Nicolay (2012). Molecular MRI of Atherosclerosis, Molecular Imaging, Prof. Bernhard Schaller (Ed.), ISBN: 978-953-51-0359-2, InTech, Available from: http://www.intechopen.com/books/molecularimaging/molecular-imaging-of-atherosclerosis

\section{INTECH}

open science | open minds

\section{InTech Europe}

University Campus STeP Ri

Slavka Krautzeka 83/A

51000 Rijeka, Croatia

Phone: +385 (51) 770447

Fax: +385 (51) 686166

www.intechopen.com

\section{InTech China}

Unit 405, Office Block, Hotel Equatorial Shanghai

No.65, Yan An Road (West), Shanghai, 200040, China

中国上海市延安西路65号上海国际贵都大饭店办公楼405单元

Phone: +86-21-62489820

Fax: +86-21-62489821 
(C) 2012 The Author(s). Licensee IntechOpen. This is an open access article distributed under the terms of the Creative Commons Attribution 3.0 License, which permits unrestricted use, distribution, and reproduction in any medium, provided the original work is properly cited. 